\title{
Development of Feet Edema on Contact with a Cemented Floor in Specific Individuals with Genetic Predisposition
}

\author{
Kong Derick Njikeh \\ Faculty of Medicine and Biomedical Sciences, University of Yaounde I, Yaounde, Cameroon \\ Email: kongderick@yahoo.com
}

Received 7 May 2015; accepted 7 June 2015; published 10 June 2015

Copyright (C) 2015 by author and Scientific Research Publishing Inc.

This work is licensed under the Creative Commons Attribution International License (CC BY). http://creativecommons.org/licenses/by/4.0/

(c) (i) Open Access

\begin{abstract}
Edema is a sign/symptom which has origin diverse causes and mechanisms of installations. I do believe that it can be classified into appendicular and axial edemas with reference to the body division rather than the present classification of peripheral edema and other edemas. Edema being a sign/symptom as an entity does cause other signs and symptoms in the body. From observations, I do believe that a cemented floor causes the development of feet edema in specific individuals with genetic predisposition. This can be confirmed by the fact that when these persons place their feet on somewhere else rather than the floor, they do not develop an edema.
\end{abstract}

\section{Keywords}

Edema, Appendicular, Axial, Cemented Floor, Feet, Genetic Predisposition

\section{Introduction}

Edema refers to the presence of excess fluid in the interstitial tissue spaces or body cavities (Effusion) [1] [2] Edema is presently classified into peripheral and other edemas, but I do believe that it should be classified into two main types with reference to the body division:

- The Appendicular edema which is presently known as peripheral edema. This involves the upper and lower limbs with particular predilection on the feet, ankles, legs, hands and arms. This type of edema can present itself into two forms; the pitting and non-pitting edemas.

- The Axial edema which is presently placed under other edemas. This involves the axial section of the body in particular the visceral organs such as cerebral edema, pulmonary edema and macular edema.

Edema has different causes and mechanisms of installations which have been studied. These are summarized 
below as follows [1]-[4]:

1) Increased hydrostatic pressure

- Congestive heart failure

- Constrictive pericarditis

- Liver cirrhosis

- Venous obstruction

- Lower extremity inactivity with prolonged dependency

- Failure of venous valves

- Excessive body heat/thyroid disease

- Insufficiency of sympathetic nervous system/neurohormonal dysregulation

- Vasodilator drugs

- Exposure to high altitude

- Excessive kidney retention of salt and water

2) Reduced plasma oncotic pressure

- Protein-losing glomerulopathies (nephrotic syndrome)

- Liver cirrhosis (ascites)

- Malnutrition

- Protein-losing gastroenteropathy

- Loss of protein from denuded skin areas

3) Increased blood vessel wall permeability/inflammation

- Inflammatory mediators

- Toxins

- Microbial infections (bacterias, viruses, fungietc)

- Vitamin deficiency, especially vitamin C

- Prolonged ischemia

- Burns

- Allergies

- Trauma

4) Obstruction of fluid clearance via the lymphatic system

- Cancer

- Filarial nematodes infections

- Surgery

- Congenital absence or abnormality of lymphatic vessels

- Post irradiation

Edema being a sign/symptom causes other signs and symptoms in the body which includes [3]:

- Swelling of the skin

- A stretched and shiny skin

- Skin discolouration

- Skin dimple after being pressed in the case of pitting edema

- Puffiness of the ankles, face or eyes

- Aching body parts

- Stiff joints

- Weight gain or weight loss

- Raised blood pressure and pulse rate

\section{Observation}

When certain individuals place their feet on a cemented floor, they develop a progressive edema on their feet which attains its maximum within an hour.

When their feet are placed on a floor with a carpet or on bare earth, there is no development of an edema.

\section{Explanation}

I do believe that there is a specific sensitivity of the cells that make up the endothelium of the blood and lym- 
phatic vessels in their feet which is caused by genetic predisposition. This edema can be explained in the fact that the cemented floor contains charges and when the feet are place on the floor, the sensitivity of the cell membranes in the endothelium of the blood and lymphatic vessels to the charged state of the floor causes a change in the membrane potential. This change in the membrane potential of the cells causes an increased permeability of the cell membrane due to the opening of membrane channels. Fluid then moves out by transudation into the extracellular matrix which leads to an edema. This state of transudation comes to equilibrium within an hour due to pressure equalization between the fluid in the vessels and the fluid in the interstitial space. When the feet are removed from contact with the floor, the edema subsides within an hour. This is due to the reversibility of the membrane potential to its initial state leading to normal cellular permeability and the excess fluid is then reabsorbed by the lymphatic vessels and at the veiniole part of the blood vessels.

The physiologic and pathologic causes of edema of the feet as indicated above are eliminated in these persons because when their feet are placed on a floor with a carpet or on bare earth, there is no development of an edema.

\section{Conclusion}

The installation of edema in the body has many causes. One of which could be the feet contact with a cemented floor in specific individuals with genetic predisposition. It is observed that those without this genetic predisposition do not develop feet edema when in contact with a cemented floor. So, this opens the way for case studies to be carried out for best proving this theory.

\section{References}

[1] Guyton \& Hall (2006) The Body Fluid Compartments; Extracellular and Intracellular Fluids; Interstitial Fluid and Edema. Text Book of Medical Physiology, 11th Edition, Saunders/Elsevier, Philadelphia.

[2] Kumar, Abbas, Fausto and Mitchell (2007) Hemodynamic Disorders. In: Robbins Basic Pathology, 8th Edition, Saunders/Elsevier, Philadelphia, 81-84.

[3] Nordqvist, C. (2009) What Is Edema? What Causes Edema? Medical News Today.

[4] Edema-Wikipedia, the Free Encyclopedia.htm. 